J. Dairy Sci. 102:926-926

https://doi.org/10.3168/jds.2019-102-1-0926

(๑) American Dairy Science Association ${ }^{\circledR}, 2019$.

\title{
Erratum to "Distribution of hydrophilic and lipophilic antibacterial drugs in skim milk, cream, and casein" (J. Dairy Sci. 101:10694-10702)
}

\section{Z. Ozdemir, B. Tras, and K. Uney}

On page 10697, the following sentence in the Method Validation section was incorrect: "Acceptance criteria for accuracy and precision were as $\mathrm{CV}<15 \%$ and bias within $\pm 15 \%$, respectively." The sentence should read (corrections in bold): "Acceptance criteria for precision and accuracy were as follows: CV $<15 \%$ and bias within $\pm 15 \%$, respectively."

The journal regrets the error.

\section{REFERENCES}

Ozdemir, Z., B. Tras, and K. Uney. 2018. Distribution of hydrophilic and lipophilic antibacterial drugs in skim milk, cream, and casein. J. Dairy Sci. 101(12):10694-10702. https://doi.org/10.3168/jds.2018-14766. 